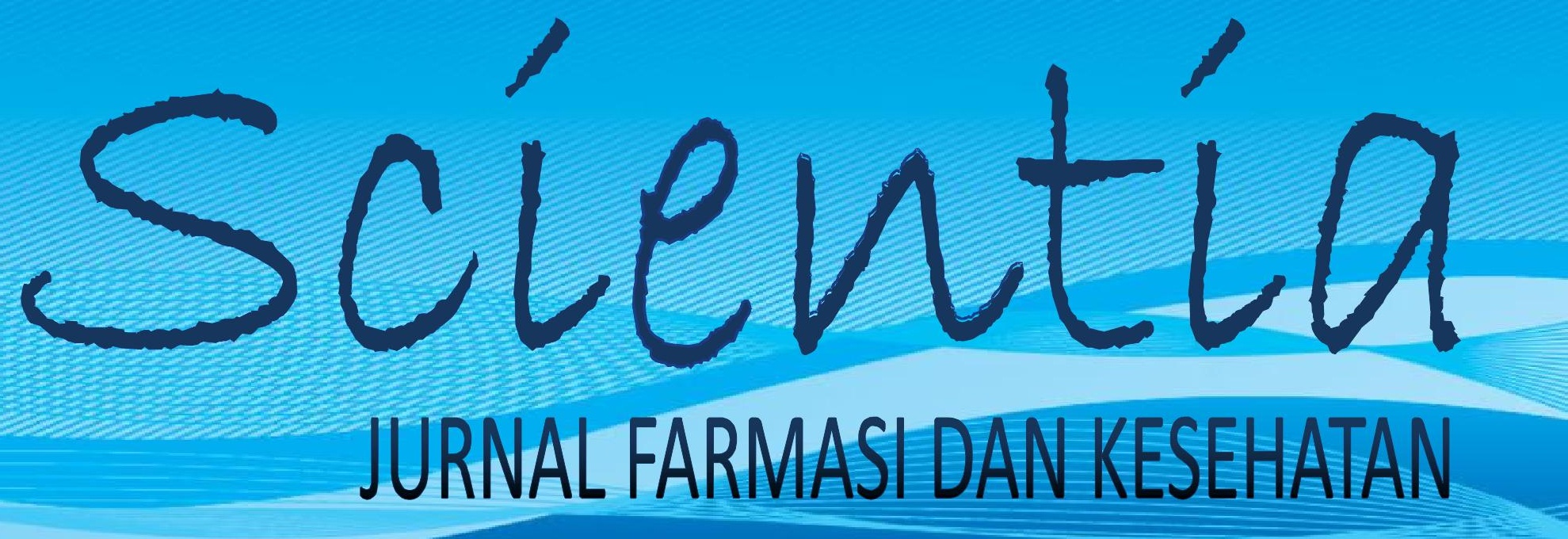

ISSN : 2087-5045

Volume 4, Nomor 2, Agustus 2014

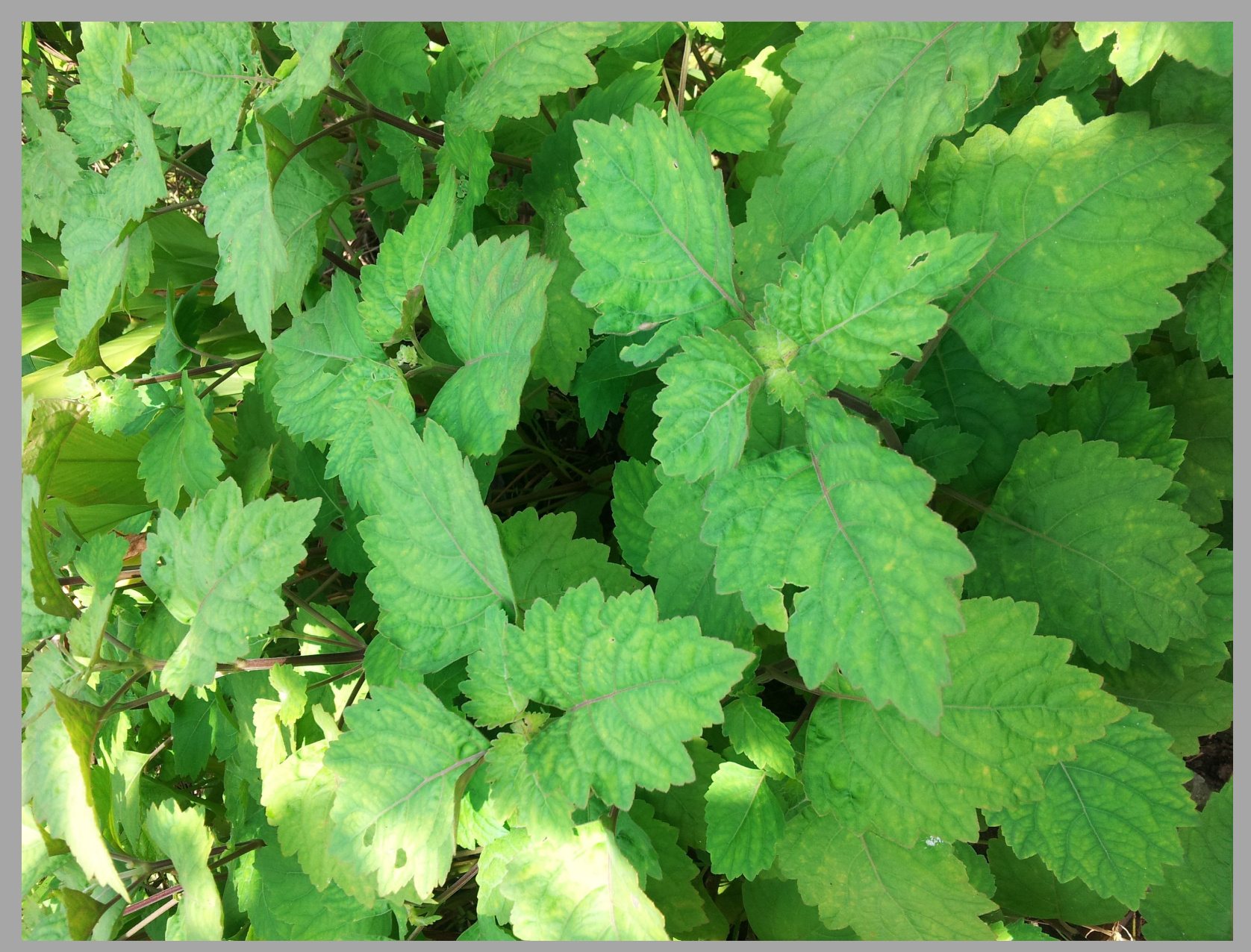

Dilebilikan oleh:
Sekolah Tinggi Farmasi Indonesia (STFI)
Yayasan Perintis Padang

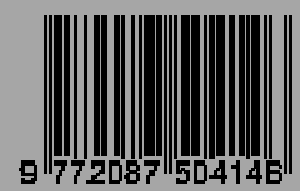




\section{SCIENTIA}

\section{JURNAL FARMASI DAN KESEHATAN}

\section{DEWAN REDAKSI}

Penanggung Jawab :

Prof. H. Syahriar Harun, Apt

\section{Pemimpin Umum :}

DR.H.M. Husni Mukhtar,MS, DEA, Apt

Redaktur Pelaksana :

Verawati, M.Farm, Apt

Eka Fitrianda, M.Farm, Apt

Sekretariat :

Afdhil Arel, S.Farm, Apt

Khairul
Dewan Penyunting :

Prof.H. Syahriar Harun, Apt

Prof.DR.H. Amri Bakhtiar,MS,DESS, Apt

Prof.DR.H. Almahdy, MS, Apt

DR.H.M. Husni Mukhtar, MS, DEA, Apt

DR. H. Yufri Aldi, MSi, Apt

Drs. B.A. Martinus, MSi

Hj. Fifi Harmely, M.Farm, Apt

Farida Rahim, M.Farm, Apt

Revi Yenti, M.Si, Apt

Verawati, M.Farm, Apt

Ria Afrianti, M.Farm, Apt

Eka Fitrianda, M.Farm, Apt

Mimi Aria, M.Farm, Apt

Dira, MSc, Apt

Penerbit :

Sekolah Tinggi Farmasi Indonesia (STIFI) Perintis Padang

ISSN : 2087-5045

Alamat Redaksi/Tata Usaha :

STIFI Perintis Padang

Jl. Adinegoro Km. 17 Simp. Kalumpang Lubuk Buaya Padang

Telp. (0751)482171, Fax. (0751)484522

e-mail : stifpadang@gmail.com

website : www.stifi-padang.ac.id 


\section{SALAM REDAKSI}

Scientia edisi Agustus 2014 ini diisi oleh penelitian bioaktivitas tumbuhan obat. Tumbuhan obat merupakan sumber daya alam yang terdistribusi luas sehingga mudah diperoleh dan sangat cocok digunakan untuk penyakit-penyakit kronis dan degeneratif. Namun perbedaan lingkungan tempat tumbuh, iklim dan cuaca menyebabkan adanya variasi komponen Fitokimia baik dari segi kualitatif maupun kuantitatif hal ini berakibat kepada bioktivitas tumbuhan obat dari spesies yang sama bisa menjadi berbeda.

Oleh kerena itu sangat dibutuhkan standarisasi obat tradisional dimulai dari proses pengumpulan tumbuhan, pembuatan ekstrak hingga pengolahannya menjadi sediaan obat. Kedepan masih sangat terbuka luas kesempatan bagi obat tradisional berkualitas untuk dapat disejajarkan dari obat sintentik.

Semoga kehadiran jurnal Scientia ini dapat memperkaya khazanah keilmuan para pembaca sekalian serta memberikan kontribusi dalam perkembangan ilmu kefarmasian dan kesehatan.

Padang, Agustus 2014

Salam Sehat

a/n Redaksi Scientia 
UJI EFEK TERATOGEN ANTI NYAMUK BAKAR YANG MENGANDUNG $46-50$ TRANSFLUTHRIN TERHADAP FETUS MENCIT PUTIH

Almahdy A, Dachriyanus, Maryorie Rosa

UJI AKTIVITAS ANTIDIABETES TIPE II EKSTRAK ETANOL SISA PENYULINGAN KULIT BATANG KAYU MANIS DENGAN INDUKSI LEMAK TERHADAP MENCIT PUTIH JANTAN

Ria Afrianti, M. Husni Mukhtar, Allen Baksir

PROSES PENYEMBUHAN LUKA BAKAR PADA MENCIT PUTIH JANTAN MENGGUNAKAN MEMBRAN PEMBALUT DARI PATI BENGKUANG (Pachyrrhizus erosus (L) Urban)

Yufri Aldi, Dedi Nofiandi, Elya Sari

FORMULASI GEL MINYAK NILAM DAN UJI DAYA HAMBATNYA

TERHADAP BAKTERI Staphylococcus aureus

Widyastuti, Farizal

UJI AKTIVITAS ANTIHIPERURISEMIA EKSTRAK ETANOL KULIT BUAH MANGGIS (Garcinia mangostana L.) DAN BUAH ASAM GELUGUR (Garcinia atroviridis Griff. ex. T. Anders.) SECARA IN VITRO

Dira, Eka Fitrianda, Novita Sari

UJI EFEK ANTIHIPERGLIKEMIA EKSTRAK ETANOL DAUN

LIDAH BUAYA (Aloe vera (L.) Webb )TERHADAP MENCIT PUTIH JANTAN YANG DI INDUKSI DEKSAMETASON

Mimi Aria, Husni Mukhtar, Ike Mulianti

PERBANDINGAN KADAR FENOLAT TOTAL DAN AKTIVITAS

Rinal Kurniawan, Syafrizar, Wilda Welis 


\title{
PROSES PENYEMBUHAN LUKA BAKAR PADA MENCIT PUTIH JANTAN MENGGUNAKAN MEMBRAN PEMBALUT DARI PATI BENGKUANG(Pachyrrhizus erosus (L) Urban)
}

\author{
Yufri Aldi ${ }^{1}$, Dedi Nofiandi ${ }^{2}$ dan Elya Sari ${ }^{2}$ \\ ${ }^{1}$ Fakultas Farmasi Universitas Andalas \\ ${ }^{2}$ Sekolah Tinggi Farmasi Indonesia Perintis Padang
}

\begin{abstract}
Study of the effect of varying the concentration of the absorption propilenglicol membrane wound dressing yam starch in the healing process of burns on white mice. The concentration of propilenglicol are used 20\%,30\%, $40 \%$ of the total analyzed poliblen. Parameter of analysis are organoleptic, membrane thickness, $\mathrm{pH}$,absorption test , antibacterial activity and pharmacological activity. The reasults show that concentrations propilenglicol effect was not significantly different in membrane thickness formula 1 and formula 2, but significantly different from the formula 3, the absorption test formula 3 have the better absorption of the formula 1 and formula 2 . in the healing process of burn, healing percentages were not significantly different in each formula, but significantly different from controls.
\end{abstract}

Keywords : Yam bean, plasticizer, membrane wound dressing, burns

\section{PENDAHULUAN}

Pembalut luka (wound dressing) berfungsi untuk menutupi atau melindungi jaringan baru, menyerap cairan yang keluar dari luka/nanah, mengurangi rasa sakit dan juga diharapkan dapat mempercepat proses penyembuhan luka. Pembalut luka primer yang kontak langsung dengan luka saat ini pada umumnya berbahan dasar karbohidrat antara lain kitoson dan alginat. Dari bahan tersebut akan dihasilkan produk pembalut luka yang berdaya serap tinggi, mudah digunakan/dilepaskan, melindungi terhadap serangan bakteri, dan menutupi luka (Mutia, 2011).

Bengkuang (Pachyrrhizus erosus (L) Urban) merupakan sumber daya alam yang memiliki prospek pengembangan yang sangat luas. Oleh karena itu dilakukan pengolahan bengkuang yang bertujuan memanfaatkan sumber daya alam yang tersedia menjadi produk yang mempunyai nilai tambah yang tinggi (Alina, 2006). Pati bengkuang telah digunakan dalam berbagai bentuk sediaan, seperti dalam bentuk bedak dingin, masker, pelembab, lotion, dan bath gel (Kusnandar, 2010).

Berdasarkan uraian diatas, mendorong peneliti untuk melakukan penelitian terhadap membran pembalut luka dari bahan pati bengkuang dengan memvariasikan konsentrasi propilenglikol.

\section{METODA PENELITIAN}

\section{Alat dan Bahan}

Alat yang digunakan adalah oven, autoklaf, erlemeyer, cawan petri, kapas, ose, tabung reaksi, spatel, mikrometer, kaca arloji, beaker glass, magnetik stirer, gelas ukur, timbangan analitik, pinset, kasa, plester, desikator, krus porselein, buret, pipet tetes, dan kaca arloji.

Bahan-bahan yang digunakan adalah neomisin sulfat, pati bengkuang, polivinil alkohol, propilenglikol, nipagin, nipasol, air suling, Staphylococcus aureus, mencit putih jantan, $\mathrm{NaCl}$ fisiologis, nutrient agar (NA), Mueller-Hilton agar, alkohol $70 \%, \mathrm{H}_{2} \mathrm{SO}_{4} 2 \mathrm{~N}$, fenolftalein $0.1 \%$, larutan iodium dan $\mathrm{NaOH} 0,1$ $\mathrm{N}$.

\section{Pembuatan pati bengkuang}

Umbi bengkuang (Pachyrrhizus erozus (L) Urban) diambil di daerah Kecamatan Koto Tangah, Padang. $3 \mathrm{~kg}$ umbi bengkuang yang 
telah dikupas dan dibersihkn, dipotong kecil, diblender diperas dan disaring, sehingga diperoleh sari bengkuang. Sari bengkuang diendapkan. Endapan yang diperoleh dikeringkan, digerus dan diayak. Sehingga diperoleh pati bengkuang.

\section{Pembuatan membran pembalut luka}

Tabel 1. Formula Membran Pembalut Luka

\begin{tabular}{|c|l|c|c|c|}
\hline No & \multicolumn{1}{|c|}{ Nama Zat } & F1 & F2 & F3 \\
\hline 1 & Neomisin sulfat(gr) & 0,5 & 0,5 & 0,5 \\
\hline 2 & Pati Bengkuang(gr) & 4 & 4 & 4 \\
\hline 3 & $\begin{array}{l}\text { Polivinil } \\
\text { Alkohol(gr) }\end{array}$ & 2 & 2 & 2 \\
\hline 4 & Propilenglikol(gr) & 1,2 & 1,8 & 2,4 \\
\hline 5 & Nipagin(gr) & 0,05 & 0,05 & 0,05 \\
\hline 6 & Nipasol (gr) & 0,1 & 0,1 & 0,1 \\
\hline 7 & Aquades ad(ml) & 100 & 100 & 100 \\
\hline
\end{tabular}

Proses pembuatan membran yang di lakukan pada penelitian ini mengunakan metode tuang. Pati bengkuang, polivinil alkohol (PVA), propilenglikol, nipagin, nipasol serta neomisin sulfat ditambahkan air suling yang tersedia dalam beaker glass, kemudian diaduk dengan batang pengaduk dan dipanaskan sambil diaduk dengan magnetik stirrer. Suhu yang digunakan waktu pemanasan adalah $70^{\circ} \mathrm{C}$ selama 40 menit, Kemudian tuangkan pada cetakan membran modifikasi dan biarkan kering selama 3 hari pada suhu kamar. Membran yang sudah mengering dilepaskan dari cetakan. Kemudian dilakukan evaluasi terhadap membran pembalut luka (Anwar, 2012)

\section{Evaluasi membran pembalut luka}

\section{a. Pemeriksaan Organoleptis}

Pemeriksaan organoleptis meliputi pengamatan bentuk, warna, bau dan rasa dari membran yang dihasilkan (DepKes RI, 1995).

\section{b. Pemeriksaan pH}

Pengukuran $\mathrm{pH}$ dilakukan dengan cara 1 gr membran diencerkan dengan air suling hingga $10 \mathrm{ml}$. elektroda dicelupkan dalam wadah tersebut, biarkan jarum bergerak sampai posisi konstan. Angka yang ditunjukan $\mathrm{pHmeter}$ merupakan nilai $\mathrm{pH}$ tersebut (Martin, 1993 dan DepKes RI, 1995).

\section{c. Ketebalan membran}

Ketebalan membran diukur pada 5 titik berbeda menggunakan mikrometer kemudian dihitung nilai rata-ratanya (Krochta, 1994).

\section{d. Uji Daya Serap}

Membran di potong dengan ukuran $2 \times 2 \mathrm{~cm}$, kemudian ditimbang beratnya sebagai berat awal $(W t)$. Lalu membran di rendam dalam $5 \mathrm{ml} \mathrm{NaCl}$ fisiologis selama 1, 10, 20, 30 menit. Setelah di rendam permukaan membran dikeringkan dengan tisu kertas dan di timbang beratnya sebagai berat akhir (Wf) (Lachman, 1994).

$$
\text { Rumus : } \frac{W f-W t}{W t} \times 100 \%
$$

e. Uji aktivitas antibakteri membran pembalut luka pati bengkuang

Medium Mueller-Hilton Agar (MHA) yang telah dicairkan dimasukan dalam cawan petri steril sebanyak $10 \mathrm{ml}$ dan dibiarkan memadat (base layer). Setelah itu dibuat "seed layer" untuk bakteri uji dengan cara mencampur $5 \mathrm{ml}$ medium MHA dengan 1 $\mathrm{ml}$ suspensi bakteri Staphylococcus aureus, dihomogenkan lalu dituang di atas base layer dan dibiarkan memadat. Sediaan uji yang telah dibentuk seperti paper disc diletakkan diatas media kemudian diinkubasi pada suhu $37^{\circ} \mathrm{C}$ selama 24 jam. Diamati dan diukur zona hambatnya (Fatmawati, 2009).

f. Uji efektifitas membran pembalut luka bakar pada hewan percobaan

Hewan dikelompokkan menjadi 5 kelompok, masing-masing terdiri dari 5 ekor, yaitu; kelompok kontrol (tidak mengandung neomisin sulfat), kelompok F1, kelompok F2, kelompok F3 dan kelompok membran pembanding (Daryantulle ${ }^{\circledR}$ ). Setiap formula mengandung neomisin sulfat $0,5 \%$.

Bulu pada bagian punggung hewan dirontokkan dengan menggunakan krim perontok bulu. Bagian punggung yang telah dirontokkan bulunya dibersihkan dengan alkohol $70 \%$, selanjutnya luka bakar dibuat dengan menggunakan lingkaran logam berdiameter 1,5 $\mathrm{cm}$ yang dipanaskan dalam air panas hingga suhu $85^{\circ} \mathrm{C}$ selama 15 menit. Logam panas 
tersebut ditempelkan pada bagian punggung mencit yang telah dirontokan bulunya selama 20 detik, timbul luka berbentuk lingkaran dipunggung mencit. Luka yang terbentuk kemudian dioleskan suspensi bakteri Staphylococcus aureus dengan kapas pada seluruh permukaan luka, kemudian luka ditutupi dengan kain kasa dan diplester (Jewezt, 2012).

Setelah 24 jam terinfeksi, luka bakar dibersihkan dengan $\mathrm{NaCl}$ fisiologis kemudian ditutupi dengan membran pembalut luka pati bengkuang berdasarkan masing-masing kelompok, setelah itu ditutupi dengan kain kasa dan diplester. Selanjutnya membran yang baru di tempelkan lagi seperti prosedur diatas setiap satu hari selama 21 hari. Lakukan pengamatan pada luas daerah luka yang sembuh pada hari ke-7, ke-14, ke-21 (Mutia, 2011).

\section{HASIL DAN PEMBAHASAN}

Penggunaan pati memiliki keterbatasan apabila diaplikasikan dalam bentuk sediaan seperti film atau membran karena menghasilkan sediaan yang rapuh dalam kondisi kering dan kemampuan menyerap air yang tinggi untuk itu perlu penambahan bahan yang dapat memperbaiki sifat pati tersebut. Dalam penelitian ini menggunakan propilenglikol sebagai plasticizer. Tujuan penambahan plasticizer yaitu untuk menurunkan kekakuan dan meningkatkan fleksibilitas sediaan. Kombinasi antara propilenglikol dengan PVA akan menghasilkan sediaan yang lebih lebih kompatibel (terlihat dari film yang dihasilkan transparan dengan permukaan yang relatif rata). Pemilihan penambahan PVA pada formula dapat mempercepat proses pengeringan, dan memberikan kontak yang baik dengan kulit. Pada formula ditambahkan nipagin dan nipasol hal ini bertujuan untuk mencegah pertumbuhan jamur selama pengeringan sediaan.

Konsentrasi penambahan plasticizer pada penelitiaan ini adalah $20 \%, 30 \%, 40 \%$ dari polimer. Pemilihan konsentrasi ini berdasarkan uji pendahuluan yang telah dilakukan bahwa pada konsentrasi besar dari $40 \%$ maka membran yang terbentuk akan mengkerut dan susah diangkat dari cetakan membran. . Apabila konsentrasi propilenglikol yang digunakan kecil dari $20 \%$ membran yang dihasilkan mudah patah dan kaku.

Hasil pemeriksaan organoleptis dari membran F1, membran yang terbentuk tapi susah diangkat dari cetakan. Hal ini disebabkan karena kecilnya konsentrasi propilenglikol yang digunakan sebagai plasticizer karena plasticizer merupakan komponen yang sangat berperan dalam pembentukan membran untuk menghindari lengketnya membran pada cetakan dan tidak robek pada saat dilepas. Warnanya yang dihasilkan coklat muda, bau khas, dan berasa agak manis.

Hasil pemeriksaan organoleptis F2 dan F3 diperoleh membran yang utuh, warna coklat muda, bau khas, rasa agak manis, serta semakin mudah untuk dikeluarkan dari cetakan. Plasticizer dapat meningkatkan elastisitas dari membran. Peningkatan konsentrasi propilenglikol menyebabkan ketebalan lapisan membran semakin meningkat dan lebih fleksibilitas.

Pada pemeriksaan $\mathrm{pH}$ membran tanpa neomisin sulfat diperoleh hasil $\mathrm{pH} 7,38-7,39$ sedangkan membran F1 6,39, F2 6,20 dan F3 6,10 . Terjadinya penurunan $\mathrm{pH}$ pada Formula disebabkan adanya kandungan neomisin sulfat yang memiliki $\mathrm{pH}$ 6,7. $\mathrm{pH}$ membran yang diperoleh sudah sesuai dengan $\mathrm{pH}$ fisiologis kulit yaitu 4,2 - 6,5 (Wasitaatmadja, 1997).

Ketebalan membran pada F3 memiliki perbedaan yang signifikan $(\mathrm{p}<0,05)$ dibandingkan dengan F2 dan F1 artinya F3 lebih tebal dibandingkan dengan $\mathrm{F} 2$ dan $\mathrm{F} 1$ ini disebabkan besarnya konsentrasi propilenglikol pada F3, semakin besar konsentrasi propilenglikol maka semakin tebal sediaan membran yang dihasilkan.

Tabel 2. Hasil pengukuran ketebalan membran pembalut luka

\begin{tabular}{|c|c|}
\hline Formula & Rata-rata Ketebalan $(\mathbf{c m})$ \\
\hline F1 & $0,1272^{\mathrm{a}} \pm 0,0121$ \\
\hline F2 & $0,1300^{\mathrm{a}} \pm 0,0082$ \\
\hline F3 & $0,1360^{\mathrm{b}} \pm 0,0091$ \\
\hline
\end{tabular}

Ketebalan membrane merupakan sifat fisik yang akan mempengaruhi daya serap, dimana semakin tebal membran maka daya serapnya semakin besar terlihat pada Tabel III uji daya serap dibawah ini, dimana F3 pada menit ke 20, 30 memiliki daya serap yang lebih baik dari pada F1 dan F2. 
Tabel 3. Hasil pengukuran uji daya serap membran pembalut luka

\begin{tabular}{|c|c|c|c|}
\hline Menit ke & F1(\%) & F2 (\%) & F3 (\% \\
\hline $\mathbf{1}$ & $68,14^{\mathrm{b}} \pm 10,00$ & $85,53^{\mathrm{c}} \pm 18,59$ & $42,00^{\mathrm{a}} \pm 8,31$ \\
\hline $\mathbf{5}$ & $156,72^{\mathrm{b}} \pm 17,21$ & $156,9^{\mathrm{b}} \pm 24,58$ & $109,55^{\mathrm{a}} \pm 21,63$ \\
\hline $\mathbf{1 0}$ & $191,09^{\mathrm{a}} \pm 6,52$ & $192,13^{\mathrm{a}} \pm 12,25$ & $173,48^{\mathrm{a}} \pm 69,55$ \\
\hline $\mathbf{2 0}$ & $210,89^{\mathrm{a}} \pm 3,88$ & $234,99^{\mathrm{b}} \pm 13,09$ & $242,88^{\mathrm{b}} \pm 11,71$ \\
\hline $\mathbf{3 0}$ & $224,84^{\mathrm{a}} \pm 4,20$ & $239,93^{\mathrm{ab}} \pm 14,04$ & $257,24^{\mathrm{b}} \pm 10,21$ \\
\hline
\end{tabular}

Aktivitas antibakteri dari membran dapat dilihat pada tabel III, dimana secara statistik tidak ada perbedaan bermakna antara F1, F2 dan F3, artinya bahwa semua formula memiliki daya hambat yang sama terhadap bakteri.
Dari hasil uji statistik persentase penyembuhan luka tidak ada perbedaan secara bermakna antara semua formula dengan pembanding mencit, namun berbeda nyata dengan kontrol.

Tabel 4. Aktifitas antibakteri membran pembalut luka

\begin{tabular}{|c|c|c|}
\hline Kelompok & $\begin{array}{c}\text { Diameter daya } \\
\text { hambat }(\mathbf{m m})\end{array}$ & Keterangan \\
\hline Kontrol & $0,00^{\mathrm{a}} \pm 0,00$ & Resisten \\
\hline Formula 1 & $19,91^{\mathrm{b}} \pm 0,0224$ & Sensitif \\
\hline Formula 2 & $19,92^{\mathrm{b}} \pm 0,0274$ & Sensitif \\
\hline Formula 3 & $19,92^{\mathrm{b}} \pm 0,0274$ & Sensitif \\
\hline
\end{tabular}

Tabel 5. Persentase penyembuhan luka bakar pada putih jantan.

\begin{tabular}{|c|c|c|c|}
\hline Kelompok & $\begin{array}{c}\text { Persen penyembuhan } \\
\text { pada hari ke 7 }\end{array}$ & $\begin{array}{c}\text { Persen penyembuhan } \\
\text { pada hari ke 14 }\end{array}$ & $\begin{array}{c}\text { Persen penyembuhan } \\
\text { pada hari ke 21 }\end{array}$ \\
\hline Kontrol negatif & $5,19^{\mathrm{a}} \pm 7,11$ & $57,11^{\mathrm{a}} \pm 3,89$ & $100 \pm 0,00$ \\
\hline F1 & $31,41^{\mathrm{b}} \pm 91,67$ & $72,52^{\mathrm{b}} \pm 8,87$ & $100 \pm 0,00$ \\
\hline F2 & $31,41^{\mathrm{b}} \pm 91,67$ & $72,52^{\mathrm{b}} \pm 8,87$ & $100 \pm 0,00$ \\
\hline F3 & $39,78^{\mathrm{b}} \pm 11,56$ & $79,03^{\mathrm{b}} \pm 7,59$ & $100 \pm 0,00$ \\
\hline Pembanding & $29,38^{\mathrm{b}} \pm 6,19$ & $71,39^{\mathrm{b}} \pm 7,23$ & $100 \pm 0,00$ \\
\hline
\end{tabular}

\section{KESIMPULAN}

Dari hasil penelitian yang telah dilakukan dapat disimpulkan sebagai berikut :

1. Variasi konsentrasi propilenglikol pada membran pembalut luka pati bengkuang memberikan daya serap yang lebih besar.

2. Proses penyembuhan luka bakar pada mencit putih yang di induksi dengan logam panas menggunakan 3 variasi Formula hasilnya tidak berbeda $(\mathrm{P}>0,05)$.

\section{DAFTAR PUSTAKA}

Alina W, Ersa CB, Fitrianti D, Apriyanti dan Lestari R, 2006, Industri Makanan Dan Minuman Berbasis Bengkuang, Kumpulan Makalah PKMP PIMNAS XIX , Universitas Muhamadiyah Malang.

Anwar E, 2012, Eksipien Dalam Sediaan Farmasi Karakteristik dan Aplikasi, Penerbit Dian Rakyat, Jakarta

Departemen Kesehatan Republik Indonesia, 1995, Farmakope Indonesia, Edisi IV, Dirjen POM, Jakarta.

Fatmawati A, Mufidah, Sartini dan Halilintar VD, 2009, Aktifitas Antibakteri Krim Ekstrak Daun Kakurang (Stacytarpheta 
Jamaicensis (L) Vahl) Terhadap Stapylococcus aureus dan Pseudomonas aeruginods secara in vitro, Majalah Farmasi dan Farmakologi Vol. 13 No. 3, hal 71-75.

Jawetz E, Melnick JL dan Adelberg EA, 2012. Mikrobiologi Kedokteran edisi 25.Jakarta :EGC Penerbit Buku Kedokteran

Krochta JM, EA Baldwin, and MO NisperosCarriedo., 1994, Edible Coating and Film to Improve Food Quality, Technomic Publishing Company, New York, NY.

Kusnandar F, 2010, Kimia Pangan Komponen Makro, Dian Rakyat, Jakarta.

Lachman L, Lieberman and JL Kaning, 1994, Teori dan Praktek Farmasi Industri II, Edisi 3, alih bahasa oleh S.Suyami, Penerbit Universitas Indonesia, Jakarta.

Mutia T, Eriningsih R dan Safitri R, 2011, Membran Alginat Sebagai Pembalut Luka Primer dan Media Penyampaian Obat Topikal Untuk Luka Yang Terinfeksi, Jurnal Riset Industri Vo.V, No.2,2011, Hal 161-174.

Wasiatmadja SM., 1997, Penuntun Ilmu Kosmetik Medik, Universitas Indonesia, Jakarta. 